\title{
Adult Bochdalek Hernia
}

\author{
Wg Cdr A Alam*, Gp Capt BN Chander ${ }^{+}$
}

MJAFI 2005; $61: 284-286$

Key Words: Bochdalek hernia

\section{Introduction}

$\mathrm{B}$ ochdalek hernia is a type of congenital diaphragmatic hernia that primarily manifests in children. It is rare in adults and accounts for about $0.17 \%$ to $6 \%$ of all diaphragmatic hernias [1,2]. Bochdalek hernia affects approximately 1 in 2200 to 12,500 live births and was first described by Vincent Alexander Bochdalek in 1848 [3].

Presentation of a Bochdalek hernia in an adult is exceptionally rare, Kirkland in 1959 published the first review of 34 cases of adult Bochdalek hernia and as of 1992 only 100 cases of symptomatic adult Bochdalek hernia have been reported in world literature [4], however with the growing use of abdominal CT this abnormality is being increasingly detected in asymptomatic individuals. Quite often an adult Bochdalek hernia is detected as an incidental finding on CT scan of the abdomen in asymptomatic adults; alternatively it may be diagnosed only after complications occur.

The clinical presentation of adult Bochdalek hernia is varied and is mainly confined to the respiratory or gastrointestinal systems; which makes the diagnosis even more difficult. Imaging plays an important role in diagnosing and assessing the contents of the hernia and at the same time evaluating the presence of any associated abnormality.

We report a case of right-sided Bochdalek hernia in an adult who presented with symptoms of dyspepsia. The aim of this report is to present a rare case of adult presentation of Bochdalek hernia and also to emphasize the importance of clinical suspicion and the significant role of imaging in the accurate diagnosis of this abnormality.

\section{Case Report}

A thirty five year old male presented with breathlessness on routine exertion and symptoms of dyspepsia of a year duration. General physical examination was unremarkable, auscultation of the chest revealed presence of bowel sounds in the right side of the chest. Chest radiograph revealed a raised right hemidiaphragm, with its outlines not well discernible, mediastinal shift to the left and presence of air filled bowel loops in the right thoracic cavity (Fig 1). A provisional diagnosis of right sided diaphragmatic hernia was made and an upper gastrointestinal barium study was done which revealed presence of stomach, small intestine and parts of colon in the right thoracic cavity (Fig 2). A contrast enhanced CT scan of the thorax and abdomen was performed which

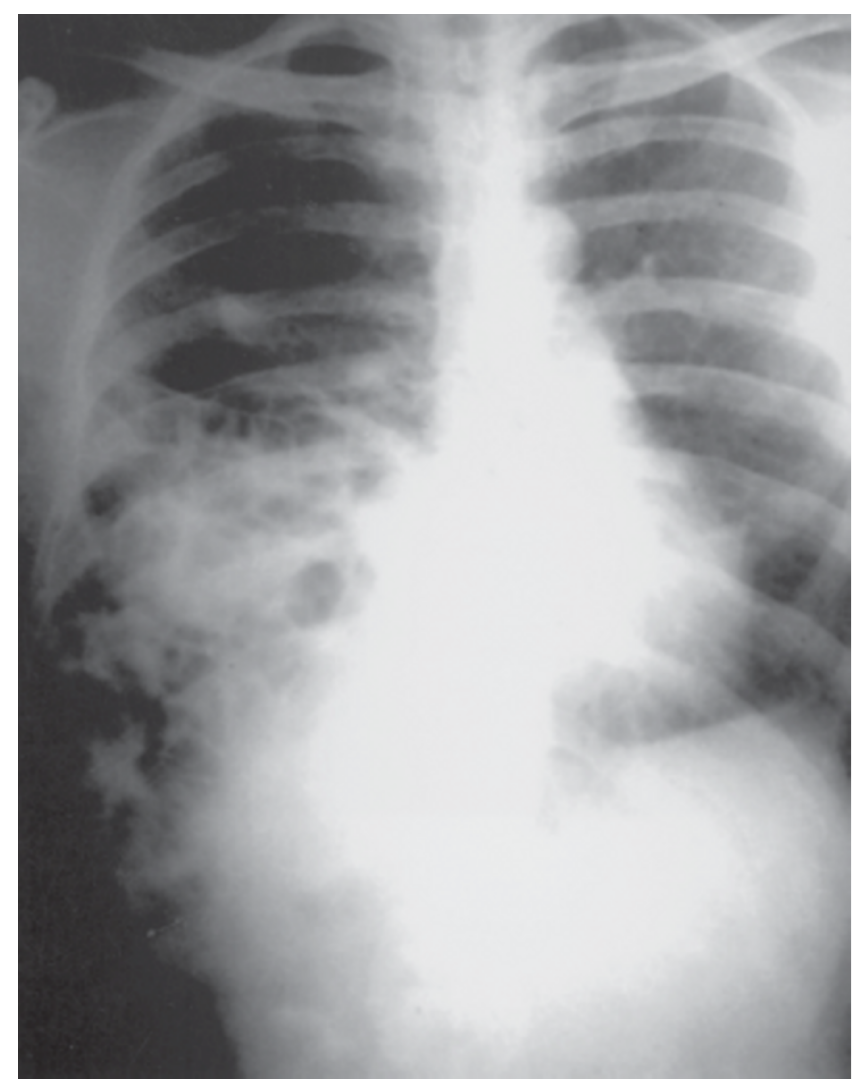

Fig. 1: Chest radiograph PA view showing raised right hemidiaphragm and presence of air filled bowel loops in the right thoracic cavity

\footnotetext{
*Associate Professor, Department of Radiodiagnosis and Imaging, Armed Forces Medical College, Pune-40 +Senior Advisor, Department of Radiodiagnosis and Imaging, Command Hospital (Air Force) Bangalore.
}

Received : 05.08.2003; Accepted : 09.10.2004 


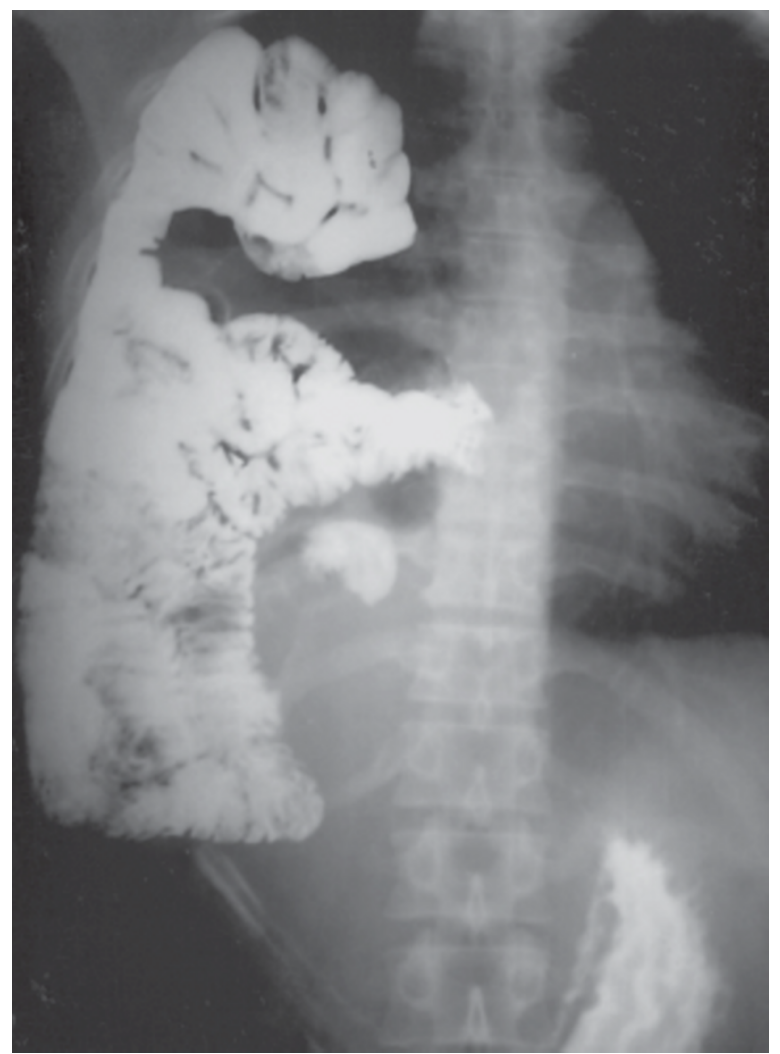

Fig. 2: Upper GI barium studies showing presence of stomach, small intestine and parts of colon in the right thoracic cavity

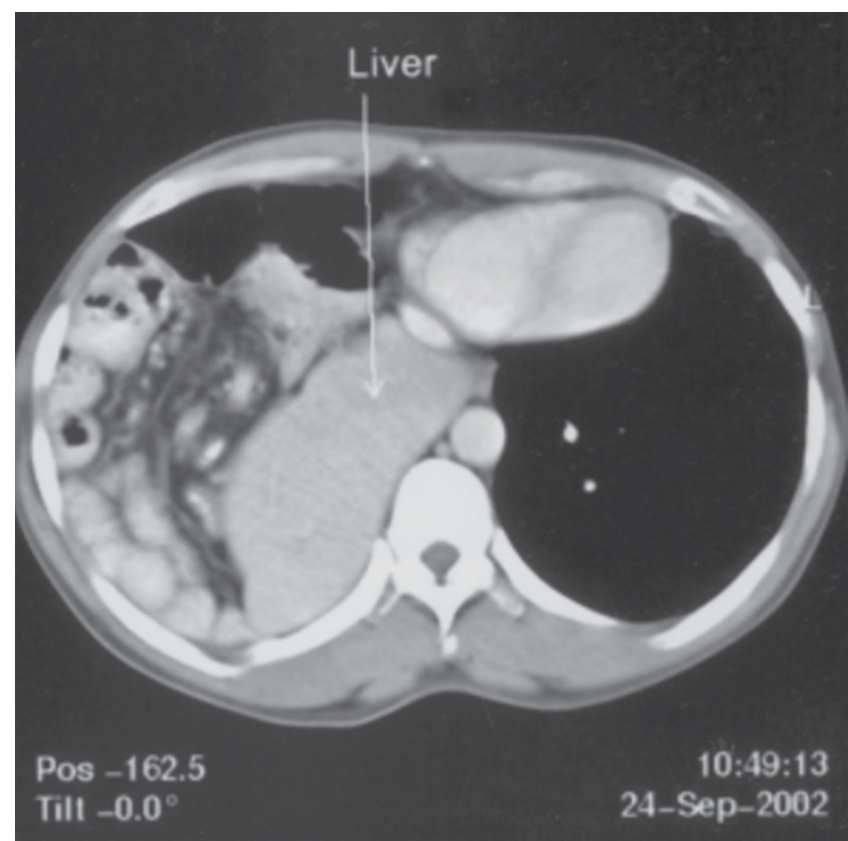

Fig. 3 : Contrast enhanced CT of the abdomen showing presence of stomach, small intestine, large intestine and the right lobe of liver in the postero-lateral aspect of the thoracic cavity

confirmed presence of stomach, small intestine, large intestine and the right lobe of liver in the postero-lateral aspect of the thoracic cavity, discontinuity of the soft tissue line of the diaphragm with continuity of sub-diaphragmatic and supradiaphragmatic densities through the defect suggestive of Bochdalek hernia (Fig 3). The right lobe of the liver was also

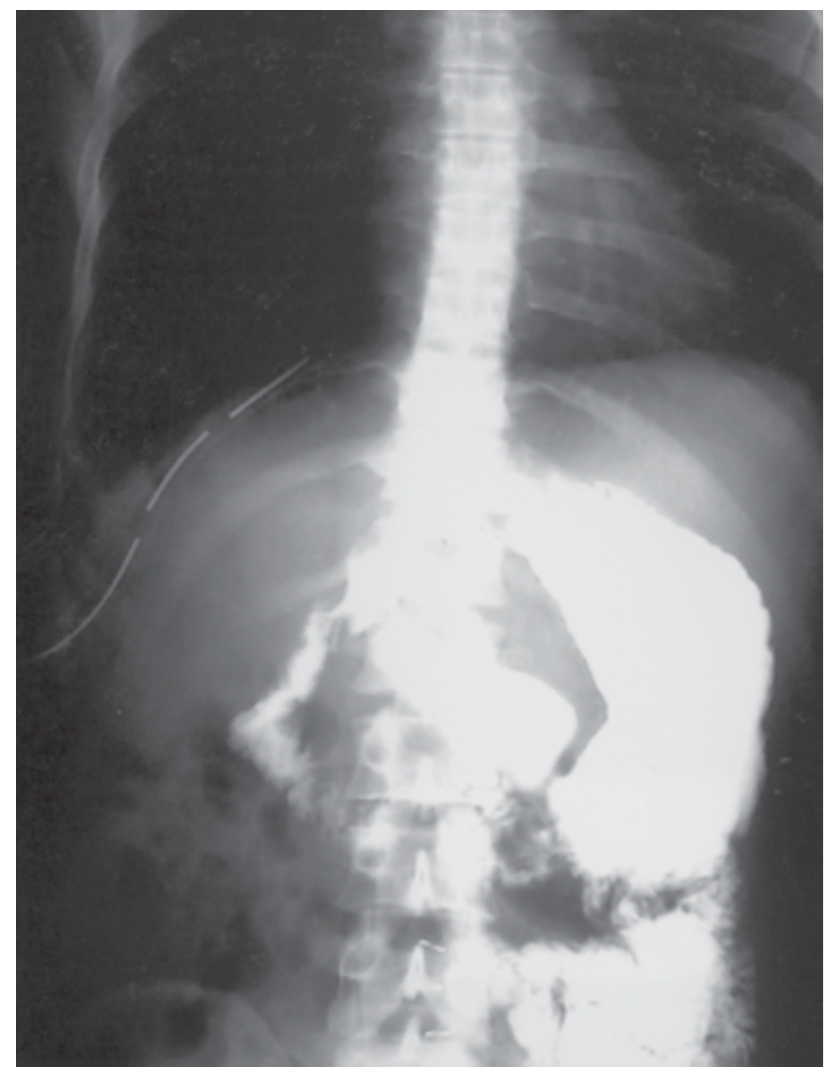

Fig. 4: Post operative upper GI barium studies showing no evidence of bowel loops in the thoracic cavity

hypoplastic. The patient was taken up for surgery and per operative findings revealed herniation of the stomach, coils of jejunum, ileum and colon through a smooth circular defect of $6 \mathrm{~cm} \times 4 \mathrm{~cm}$ size in the posterolateral aspect of the right hemidiphragm. The right lobe of the liver was hypoplastic and had herniated into the thoracic cavity. No hernial sac could be identified. The diaphragmatic defect was closed with polypropylene mesh and sutured in two layers with interrupted non-absorbable suture and the thoracic cavity was drained by a single chest tube. The patient had an uneventful postoperative recovery. A repeat upper GI barium study after 10 days of surgery revealed no evidence of any herniated bowel loop in the thoracic cavity (Fig 4).

\section{Discussion}

The foramen of Bochdalek is a $2 \mathrm{~cm} \times 3 \mathrm{~cm}$ opening in the posterior aspect of the diaphragm in the foetus, through which the pleuroperitoneal canal communicates between the pleural and peritoneal cavities. This canal normally closes by the $8^{\text {th }}$ week of gestation, failure or incomplete fusion of the lateral (costal) with the posterior (crural) components of the diaphragm leads to the development of Bochdalek hernia. Since the left canal closes later than the right, this type of hernia is found on the left side in $85 \%$ of cases [5]. The organs that most commonly herniate into the thorax through this defect are stomach, ileum, colon and spleen. The liver and the right kidney may herniate along with the bowel loops if the defect is on the right side as in our patient. 
This clinical presentation in adults and paediatric age group is different. In neonates and infants it may present with respiratory distress and cyanosis. Presentation of Bochdalek hernia in adults is varied and patients often present with chest pain, difficulty in breathing, abdominal pain and even features of intestinal obstruction. It is believed that the delay or absence of symptoms may be due to occlusion of the diaphragmatic defect by the intraabdominal viscus [6]. Our patient presented with features of dyspepsia and breathlessness on routine exertion. Since the clinical presentation is varied, a high degree of clinical suspicion coupled with imaging studies lead to an early and accurate diagnosis. The diagnosis of Bochdalek hernia can be made by conventional radiological methods like plain radiographs and barium studies.

Ultrasonography also has a role to play in the antenatal diagnosis of this condition; a level 3 ultrasound examination is the criterion standard for reaching a diagnosis of congenital diaphragmatic hernia in utero. Features indicative of congenital diaphragmatic hernia are polyhydramnios, presence of intrathoracic stomach bubble, mediastinal and cardiac shift away from the side of herniation and rarely fetal hydrops. In the post natal evaluation of diaphragmatic hernia, ultrasonography can assist in delineating the diaphgram in its entirety and also in evaluating the viscera that has herniated into the thoracic cavity [7].

Computed Tomography is believed to be the most accurate method of diagnosing and evaluating the contents of these hernias especially the smaller ones $[3,8]$. CT with multiplanar reconstructions can accurately assess the thoracic cavity and also detect any other associated anomalies like hypoplasia of the right lobe of the liver as was seen in our case. In adults since the diagnosis is usually missed unless there is a high index of suspicion, CT has an increasingly important role to play. Without the use of CT nearly $38 \%$ of adults are misdiagnosed as pleural effusion, empyema, lung cyst and pneumothorax [9]. Left sided Bochdalek hernias have reportedly been associated with lung hypoplasia, extralobar sequestration, mal-rotation of the mid-gut and cardiac defects, whereas, right sided hernias are generally associated with hypoplasia of the right lobe of the liver as was seen in our case [10].

The treatment of Bochdalek hernia is operative and patients generally do not have any recurrence and remain asymptomatic. The late presentation of this abnormality poses a difficulty in diagnosis and hence a careful examination, strong index of suspicion and imaging studies like Computed Tomography are needed to reach a correct diagnosis.

\section{References}

1. Mark E, Jeffrey SS, Saini SS, Peter RM. Prevalence of incidential Bochdalek's hernia in a large adult population. AJR 2001;177:363-66.

2. Gale ME. Bochdalek hernia: prevalence and CT characteristics Radiology 1985;156:449-52.

3. Shin MS, Mulligan SA, Baxley WA, Ho KJ. Bochdalek hernia of diaphragm in the adult. Diagnosis by computed tomography. Chest 1987;92:1098-1101.

4. MarFan MJ, Coulson ML, Siu SK. Adult incarcerated rightsided Bochdalek hernia. Aust NZ J Surg.1999;69:239-41.

5. Nyhus L, Condon R. Hernia. $4^{\text {th }}$ ed. Philadelphia, Pa: JB. Lippincott Co; 1995: 555-66.

6. Nitecki S, Bar-Maor JA. Late presentation of Bochdalek hernia: our experience and review of literature. Isr J Med Sci. 1992;28:711-4.

7. Oldham KT, Colombani PM, Foglia RP: Congenital diaphragmatic hernia. In: Surgery of Infants and Children : Scientific principles and practice. Philadelphia, Pa: JB Lippincot; 1997:883-95.

8. Wilbur AC, Gorodetsky A, Hibbeln JF. Imaging findings of adult Bochdalek hernias. Clin Imaging 12994;18(3):224-9.

9. Thomas S, Kapur B. Adult Bochdalek hernia-Clinical features, management and results of treatment. Jpn J Surg 1991;21(1);114-9.

10. Marleta R. Diaphragmatic anomalies. In: Raffensperger JG, editor. Swenson's Textbook of Paediatric Surgery; $5^{\text {th }}$ ed. NewYork: Appleton and Lange; 1990:721-35. 